\title{
Recursos literarios empleados por Leila Guerriero en sus perfiles periodísticos
}

\author{
Literary resources used by Leila Guerriero in her journalistic profiles
}

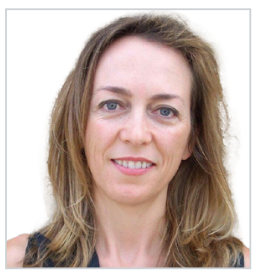

\begin{abstract}
Marta del Riego Anta. Doctoranda en el programa de Comunicación Social de la Escuela Internacional de Doctorado de la Universidad CEU San Pablo, Madrid, investiga en torno al género del perfil en Leila Guerriero. Licenciada en Ciencias de la Información por la Universidad Complutense y Máster de Periodismo de El País por la Universidad Autónoma. En el ámbito profesional, ha ejercido el periodismo en Londres y Berlín; ha trabajado en Canal Plus, Marie Claire y, durante una década, ha sido redactora jefe de la revista Vanity Fair. Actualmente es columnista del diario La Nueva Crónica, directora de Comunicación en la agencia MAHALA Comunicación, especializada en cultura, y profesora en el Máster de Periodismo Cultural de la Universidad CEU San Pablo. Universidad CEU San Pablo, Madrid, España mar.delriego.ce@ceindo.ceu.es ORCID: 0000-0001-9694-7095
\end{abstract}

Recibido: 08/08/2020 - Aceptado: 21/10/2020

Resumen:

El perfil o profile es uno de los grandes géneros del New Journalism y del periodismo anglosajón en general. En las últimas tres décadas ha vivido un auge dentro del periodismo narrativo en español y entre las periodistas que han contribuido a ello se encuentra Leila Guerriero. El objetivo de este artículo es mostrar la diversidad de recursos literarios que emplea Guerriero en sus perfiles. Para ello, hemos realizado un análisis de contenido de sus perfiles basándonos, por un lado, en las categorías establecidas por Gérard Genette y, por otro, en el modelo de análisis de los recursos literarios del profesor Domínguez Caparrós. El resultado nos ha permitido demostrar que los perfiles de Guerriero entroncan con el New Journalism estadounidense a la vez que aportan una visión distinta y personal del mismo y una forma original de escribir periodismo narrativo que los acerca a la categoría de obra literaria. Palabras clave:

Géneros periodísticos; perfil; periodismo narrativo; Nuevo Periodismo Latinoamericano; Leila Guerriero.
Received: 08/08/2020 - Accepted: 21/10/2020

\section{Abstract:}

The journalistic profile is one of the great genres of the New Journalism, and generally speaking, of Anglo-Saxon journalism as well. In the last three decades, the profile has experienced tremendous growth within narrative journalism in the Spanish language, and one of its contributors has been Leila Guerriero. The objective of this article is to present the literary resources that Guerriero uses in her profiles. To this end, we have carried out a content analysis of her profiles based on the categories established by Gérard Genette, as well as the literary resource analysis model of Professor Domínguez Caparrós. The results of our study have allowed us to demonstrate that Guerriero's profiles are linked to the New Journalism of the USA, while at the same time they provide a distinct, personal vision of such journalism, in addition to an original way of writing narrative journalism that brings it closer to the domain of literature.

\section{Keywords:}

Journalistic genres; profile; narrative Journalism; the New Latin American Journalism; Leila Guerriero.

Cómo citar este artículo:

Del Riego Anta, M. (2020). Recursos literarios empleados por Leila Guerriero en sus perfiles periodísticos. Doxa Comunicación, 31, pp. 187-205. 


\section{Introducción}

"Más que hacer preguntas, hacer un buen perfil es el arte de mirar. Nuestra labor está en revisar la leyenda que una persona cuenta de sí misma", afirma Leila Guerriero en el taller Periodismo narrativo: reporteo, mirada y estilo que impartió el 24 de mayo de 2017 en la Fundación Gabo (Fundación Gabo, 2017). En esta definición ya se encuentran características básicas del perfil: es "el arte de mirar" -al perfilado-, y consiste en "revisar la leyenda que una persona cuenta de sí misma”. Es decir, el perfil es una investigación periodística sobre una persona y pone el foco en lugares en los que nadie lo había puesto antes, tratando de iluminar sus zonas oscuras.

El término perfil, profile, ha sido ampliamente reconocido y utilizado en el periodismo anglosajón. Según Johnson (1972) ya se hablaba de él en 1925 en una de las grandes revistas del periodismo literario como The New Yorker y se recogía en manuales clásicos como el de Brennecke y Clark, Magazine article writing, de 1942. Los perfiles publicados por la revista The New Yorker influyeron decisivamente en el desarrollo y consolidación del género (Friedlander y Lee, 1988: 203): "Para las revistas, los perfiles tienden a tener las características dadas por The New Yorker, que acuñó el término y estableció un alto nivel por el cual se juzgan todavía los perfiles". El New Journalism estadounidense lo convirtió en los años 60 y 70 en uno de sus géneros estrella gracias a la proliferación de revistas con interés y espacio suficiente para encargar a sus colaboradores perfiles de largo aliento. Esquire, Rolling Stone, Harper's Magazine o The New York Times Magazine, entre otras, publicaron perfiles firmados por periodistas tan célebres ahora como Gay Talese o Norman Mailer.

Su introducción en el periodismo en español ha sido más lenta. Solo en las últimas tres décadas se ha definido como tal, con características propias que lo diferencian de otros géneros similares, denominados "biográficos" como la semblanza o la entrevista de personalidad. Aunque no aparece en los manuales de Estilo de El Mundo, ABC y Vocento. Se lo nombra en el Libro de Redacción de La Vanguardia (2004), pero como parte del género del reportaje y sin fecha ni firma. En la edición de 2002 del Libro de Estilo de El País se lo considera como un subgénero de la entrevista. En la edición de 2014, el Libro de Estilo de El País añade que "mezcla elementos del reportaje y de la entrevista de declaraciones" (2014: 51). Además, apenas existen investigaciones teóricas y solo un manual básico dedicado exclusivamente a este género: El perfil periodístico (2010), de Belén de Rosendo.

Sin embargo, en las dos últimas décadas varios autores han empezado a catalogarlo entre los géneros periodísticos. Vilamor (2000) distingue entre géneros informativos -entre los que incluye el perfil, la biografía, la semblanza y el obituario-y géneros de opinión y géneros infográfico y digital. De esa forma concede a los formatos biográficos su propia entidad (2000: 52). López Pan y Sánchez (1998) en su Tipología de géneros periodísticos en España. Hacia un nuevo paradigma clasifican los géneros en torno a criterios de actualidad entre: géneros de reporterismo de actualidad inmediata como la noticia y la crónica, y de actualidad amplia como el reportaje, la entrevista y el perfil (1998: 15-35). Alex Grijelmo en $E l$ estilo del periodista (2014) marca diferencias entre dos géneros similares al perfil: la entrevista-perfil y el reportaje-perfil. Describe la entrevista-perfil como "otra manera de escribir entrevistas en las que quepan la interpretación y la descripción” (2014: 111), y el reportaje-perfil como un reportaje que se ciñe a una persona o personalidad (2014: 74-75).

A esto se suma el nacimiento de una miríada de revistas dedicadas al periodismo narrativo en español -tanto en papel como en digital-, que ha contribuido decisivamente a ese auge del perfil y a la eclosión de una nueva generación de perio- 
distas, entre los que destaca la argentina Leila Guerriero. Guerriero es una de las grandes representantes del periodismo narrativo en español y ha cultivado todos los géneros con maestría, aunque es en el perfil donde ha alcanzado las mayores cotas de excelencia y originalidad. Sin embargo, su obra aún no ha sido objeto de estudio y es esa una carencia que el presente artículo pretende subsanar.

El objetivo de este estudio es demostrar que los perfiles de Leila Guerriero entroncan con el New Journalism estadounidense, a la vez que aportan una visión distinta y personal del mismo. Guerriero se vale de gran parte de los recursos del New Journalism que ya enumeró Tom Wolfe en El Nuevo Periodismo (1973) como la construcción de escenas sin orden cronológico y el retrato global del ambiente, del personaje principal y de los personajes secundarios. Pero este trabajo quiere demostrar que su contribución es original. En resumen, la intención es comprobar si el periodismo que practica Leila Guerriero es un modo original de hacer periodismo narrativo y, en concreto, si ha aportado una forma original de escribir perfiles que los acerca a la categoría de obra literaria.

\section{Metodología}

La presente investigación abordará el estudio de los perfiles de Leila Guerriero a través del análisis de contenido clásico basado en la lectura como instrumento de recogida de información, lectura que a diferencia de la lectura común debe realizarse siguiendo el método científico, es decir, debe ser, según Kerlinger (2002), sistemática, objetiva, replicable, y valida; y permite conocer científicamente tanto los "significados" (análisis temático) como los "significantes" (los rasgos formales, los procedimientos, las convenciones) de un texto (Wimmer y Dominick, 1996). El análisis será sistemático por cuanto se tratará de manera similar todos los contenidos, y será objetivo puesto que se evitará cualquier sesgo personal que pueda afectar a los resultados.

En palabras de Bardin (1986: 32), el análisis de contenido se presenta como un conjunto de técnicas de análisis de comunicaciones que tiende a obtener indicadores (cuantitativos o no) por procedimientos sistemáticos y objetivos de descripción del contenido de los mensajes, al mismo tiempo que interfieren conocimientos relativos a las condiciones de producción/recepción (variables inferidas) de estos mensajes. Por tanto, podemos decir que en un texto hay una relación entre la frecuencia de aparición de ciertas unidades lingüísticas y el interés de quien produce el texto.

Abert Chillón (2014) afirma que en el periodismo existe una voluntad de obra literaria, de usar los recursos de la literatura, el lenguaje y el estilo para poder contar "de modo fehaciente" la realidad (2014: 15-16). Desde ese punto de vista, que es el que adopta este estudio, en el análisis de los elementos narrativos de una obra periodística -no ficción- y de una obra de ficción se emplearían las mismas herramientas. Por esa razón, para estudiar el estilo en los perfiles de Leila Guerriero se partirá de las teorías de uno de los grandes críticos literarios y padre de la narratología, Gérard Genette (1989), que creo un diagrama temporal para los relatos -el récit, el orden real de los sucesos del texto; l'histoire, la secuencialidad real de los sucesos; y la narration, el acto de relatar y su propio devenir temporal- de muy útil aplicación en los textos periodísticos. Genette propone un análisis de texto en relación con los problemas del relato: distorsiones temporales de orden, distorsiones temporales de duración, frecuencia, modo y voz. 
¿Qué es el lenguaje literario? ¿Están escritos los perfiles de Leila Guerriero en lenguaje literario? El catedrático de Teoría de la Literatura José Domínguez Caparrós explica sobre el lenguaje literario en su Introducción al comentario de textos (1985):

Desde el formalismo ruso a nuestros días, no han sido pocos los intentos de encontrar lo específico del lenguaje literario. El problema, que ya se había planteado de otra forma en la vieja Retórica, es saber si el lenguaje literario es diferente y, en caso de responder afirmativamente, respecto a qué difiere: ¿cuál es la norma de la que se aparta el lenguaje literario?, ¿cuál es la gramática de la lengua literaria? (1985: 14).

Para resolver estas cuestiones, Domínguez Caparrós propone un modelo de análisis de texto en el que distingue entre sistema y referencia. Dentro del sistema estaría la palabra (morfología), la frase (sintaxis) y la significación (semántica). El presente estudio utilizará este modelo, que considera muy clarificador, para estudiar los recursos literarios de Guerriero, destacando los más eficaces para lograr una expresión literaria intensa y propia.

En cuanto al universo, se ha hecho un estudio de caso de los perfiles de Leila Guerriero publicados en diversos medios entre 2001 y 2012 y reunidos en dos antologías, Frutos Extraños (crónicas reunidas 2001-2008) (Guerriero, 2012) y Plano Americano (Guerriero, 2013), que son las únicas antologías dedicadas exclusivamente a Leila Guerriero y que consiguen fijar una única versión de las distintas que circulan por Internet. Estas dos antologías han tenido republicaciones en varias editoriales. Esta investigación ha utilizado la de Alfaguara de 2012 y la de la Universidad Diego Portales de 2013, que fueron ambas las publicaciones originales. De la primera, de 16 textos periodísticos, 13 son perfiles y tres, crónicas; de la segunda, los 21 textos son perfiles. De esa forma se han obtenido un total de 34 perfiles de los que se deben descontar tres que se repiten, es decir, que habría 31 perfiles antologados. A ellos se añaden los dos libros-perfil publicados por Leila Guerriero: Una historia sencilla (Guerriero, 2013) y Opus Gelber (Guerriero, 2019). Esta investigación considera pertinente incluir en el corpus de perfiles el estudio de los perfiles-libro porque forman parte del trabajo periodístico de Guerriero, puesto que su estructura y estilo son los mismos que los de los perfiles publicados en medios, y comparten con éstos su falta de actualidad inmediata, otra de las características de los perfiles de la periodista. El único rasgo que los diferencia de los perfiles publicados en medios es su larga extensión, pero precisamente esa extensión es la que proporciona un vasto campo de posibilidades para la investigación de los recursos literarios. Así, sumando los perfiles publicados en medios con los dos perfiles-libro se obtendría un corpus de 33 perfiles, que es sobre el que este estudio ha trabajado.

\section{Análisis del perfil en la obra de Leila Guerriero}

\subsection{Biografía}

Leila Guerriero nació en 1967 en Junín, provincia de Buenos Aires. Se graduó en la carrera de Turismo, en la Universidad de Junín, que nunca ejerció, y en la de Letras en la Universidad de Buenos Aires. En 1992 dejó un relato titulado Kilómetro cero en la recepción del periódico argentino de Buenos Aires Página/12, cuyo suplemento cultural, Página/30, coordinado por el escritor Rodrigo Fresán, solía publicar cuentos de lectores. Esta vez no solo publicaron el relato de Guerriero, sino que, además, la contrataron. Su primer encargo fue un reportaje sobre el caos circulatorio de Buenos Aires. Desde aquel 
reportaje hasta ahora, Guerriero ha publicado en infinidad de periódicos y revistas argentinos y latinoamericanos. Guerriero es autodidacta, nunca pasó por una facultad ni por una escuela de periodismo.

En la actualidad, Guerriero es editora para el Cono Sur de la revista Gatopardo y de la revista Travesías, directora de la colección Mirada crónica, de Tusquets Argentina, y desde 2016 dirige la Especialización en periodismo de la Fundación Tomás Eloy Martínez (Buenos Aires). A la vez que publica en medios de todo el ámbito del periodismo en español: $L a$ Nación y Rolling Stone, de Argentina; El País y Vanity Fair de España; El Malpensante y Soho, de Colombia; Etiqueta Negra, de Perú; Milenio, Letras Libres, Gatopardo y Travesías, de México; Paula, El Mercurio y Las Últimas noticias, de Chile; El País de Uruguay; Granta, del Reino Unido; entre otros. Además, ha recibido infinidad de premios de periodismo: en 2010, su texto El rastro en los huesos, publicado en El País Semanal y Gatopardo, recibió el premio CEMEX-FNPI. En 2013 ganó el premio de periodismo González Ruano de la Fundación Mapfre por su texto El bovarismo, dos mujeres y un pueblo de la Pampa, publicado en la revista colombiana El Malpensante (2012); en 2014, el Premio Konex; en 2019, el XIV Premio Internacional de Periodismo Manuel Vázquez Montalbán.

\subsection{El estilo en Leila Guerriero}

El estilo de Leila Guerriero en sus perfiles se ha convertido ya en un estilo reconocido. Para estudiarlo nos apoyaremos en las categorías del teórico literario francés Gérard Genette, quien propone un análisis de texto en relación con los problemas del relato: distorsiones temporales de orden, distorsiones temporales de duración, frecuencia, modo y voz.

Genette, en su obra Figuras III, publicada en 1972 (1989), afirma que el relato designa la sucesión de acontecimientos, reales o ficticios, que son objeto del discurso narrativo y sus diversas relaciones de concatenación, oposición, repetición, etc. Para analizar el discurso narrativo, Genette explica que ese análisis entraña "el estudio de las relaciones, por una parte, entre ese discurso y los acontecimientos que relata, por otra, entre ese mismo discurso y el acto que lo produce, real (...) o ficticiamente" (1989: 81-87).

Genette define los problemas del relato (1989: 81-87) como problemas de:

- tiempo: relaciones temporales entre relato y diégesis

- modo: modalidades de la representación narrativa

- voz: forma como se encuentra implicada en el relato la narración, la relación entre el narrador y su destinatario.

\subsubsection{Tiempo: distorsiones temporales de orden. Analepsis, prolepsis y acronía en Leila Guerriero: el ritmo (I)}

Cuando confrontamos el orden de disposición de los acontecimientos o segmentos temporales en el discurso narrativo con el orden de sucesión de esos mismos acontecimientos o segmentos temporales en la historia, se producen anacronías narrativas, es decir, diferentes formas de discordancia entre el orden de la historia y el del relato, entre ellas la analepsis y la prolepsis. 
La analepsis, según Genette, consiste en: “Toda evocación posterior de un acontecimiento anterior al punto de la historia donde nos encontramos" (1989: 104). La anacronía puede consistir también en una prolepsis: "Toda maniobra narrativa que consista en contar o evocar por adelantado un acontecimiento posterior" (Genette, 1989:121).

Guerriero utiliza analepsis y prolepsis muy a menudo, a veces incluso una dentro de la otra. A continuación, analizamos varios ejemplos del perfil del artista argentino Guillermo Kuitca. Un artista del mundo inmóvil (Guerriero, 2013). En el siguiente ejemplo hay una analepsis ("a los trece años era”) y una prolepsis ("eso que no volvería a ser en mucho tiempo: un éxito"), es decir, nos cuenta que Kuitca tuvo éxito a los 13 años, que no lo tuvo después durante mucho tiempo, pero nos anuncia que volverá a tener éxito. Guerriero utiliza una economía de medios absoluta: en una frase nos resume una vida: "A los trece años era eso que no volvería a ser mucho tiempo: un éxito" (2013: 79).

En el relato, Guerriero describe cuándo llega por primera vez a casa de Kuitca, todo se narra en presente y de pronto introduce una brevísima analepsis que da pistas de cómo es el personaje: "desaforado".

Cuando Guillemo Kuitca aparece-bajando las escaleras que llevan a los pisos superiores-no tiene aspecto de ser alguien que fue desaforado (2013: 78).

Otros ejemplos de prolepsis: en el primero hay una descripción en la que todo el párrafo está en presente hasta que con la prolepsis Guerriero anticipa que habrá más entrevistas y cómo se comportará Kuitca en esas entrevistas.

Y cuando levanta la cabeza -los ojos claros-, tiene una mirada que tendrá otras veces: compungida, enteramente triste (2013: $80)$.

En el segundo, está narrando su biografía en pasado y de pronto da un salto hacia adelante, casi como si fuera una predicción. Es una prolepsis dentro de una analepsis.

Él, mientras tanto, vivía en casa de sus padres, estaba en el centro exacto de un vórtice oscuro y, aunque no podía saberlo, Siete últimas canciones, sería la última muestra que haría en su país durante los próximos diecisiete años (2013: 83).

En Facundo Cabral. Soy leyenda, recogido en la antología Plano Americano (2013), Leila Guerriero relata un largo encuentro con el célebre cantautor argentino al tiempo que va intercalando información sobre su biografía. Hay dos planos de información: la que nos da Cabral en su conversación y la que nos da Guerriero. Y en la que nos da Guerriero anticipa con prolepsis lo que será la vida del cantautor, vida que descubriremos más adelante: son prolepsis que suenan casi a augurios.

- No tengo recuerdos de esa época. No me interesaba nada. Solo quería dormir y morir durmiendo. No quería vivir. Despertarme era una tortura. Me parecía que la vida iba a ser así siempre.

Pero la vida fue otra cosa (2013: 200).

La prolepsis es un recurso que Guerriero utiliza para suministrar pequeñas píldoras de información que hacen sostenerse el relato sobre un hilo narrativo de una tensión constante.

Además, Guerriero es capaz de narrarnos el futuro desde el pasado, es decir, en una analepsis introduce una prolepsis; o desde el futuro regresar al pasado, en una prolepsis introduce una analepsis. La maestría en lograr esos saltos temporales 
es una de las señas de identidad de su escritura. Un ejemplo de párrafo construido como analepsis con un salto hacia el futuro, prolepsis, pero que sigue siendo pasado en Facundo Cabral. Soy leyenda:

Dos días más tarde regresaba a Tierra del Fuego, en avión y con oferta de trabajo para su madre como celadora en un colegio de Tandil, sur de la provincia de Buenos Aires. Así, Facundo empezó a vivir en una ciudad donde, cuatro años después y a la luz de una vela, empezaría a vislumbrar el sexo de la mano de Mirna, la hija del zapatero, sobre las telas gastadas de un sofá muy verde (2013: 201).

\subsubsection{Tiempo: distorsiones temporales de duración}

Dentro de las distorsiones temporales de duración, Genette distingue el relato sumario o relato en el que se acelera el tiempo; la pausa descriptiva, en el que se detiene o congela el tiempo; la elipsis temporal, u omisión en la secuencia del discurso narrativo de segmentos de la historia que se narra. Esta última puede ser explícita, con indicación del tiempo transcurrido, “dos años después...”; implícita, no aparece declarada en el texto y se puede inferir del mismo; e hipotética, imposible de localizar y revelada a posteriori (1989: 144-171).

Según Genette, en el relato novelesco clásico se da un ritmo que surge de la oposición y alternancia entre relatos sumarios no dramáticos con función de espera y enlace con escenas dramáticas cuyo papel en la acción es decisivo. Como veremos a continuación, el relato de Leila Guerriero no deja intacto ninguno de los movimientos narrativos tradicionales, con lo que sus textos adquieren un ritmo especial, que va más allá incluso del ritmo del relato novelesco clásico del que habla Genette.

Para entender de dónde surge ese ritmo hay que entender primero el concepto de frecuencia. Genette explica (1989: 172) que la frecuencia narrativa son las relaciones de frecuencia entre relato y diégesis. Un acontecimiento no es solo susceptible de producirse, puede también reproducirse o repetirse. Podemos decir que un relato puede contar:

- una vez lo que ha ocurrido una vez: sería escena singulativa o singular

- $n$ veces lo que ha ocurrido $n$ veces: sería una repetición de escena singulativa

- $n$ veces lo que ha ocurrido una vez: sería un relato repetitivo

- una vez o en una sola vez lo que ha ocurrido n veces: relato iterativo.

Los perfiles de Leila Guerriero y, en general, los perfiles del Nuevo Periodismo Latinoamericano, suelen estar escritos con escenas dialogadas en tiempo real, lo que podríamos denominar "escenas singulativas". Que constituyen, a su vez, un rasgo del New Journalism estadounidense: recrear escenas con diálogos completos y descripciones detalladas del ambiente y de los personajes. En el largo perfil-libro sobre el pianista argentino Bruno Gelber (Opus Gelber, 2019), Guerriero reproduce diálogos enteros del protagonista con la narradora, o del protagonista con personas que invita a su casa, o de la narradora con alguno de sus entrevistados. Algunos son lentos, se demoran con descripciones de la voz, el tono, el aspecto, pero a menudo son rapidísimos, sobre todo los de las conversaciones telefónicas de la narradora con el protagonista:

-Hola, tesoro. Quedó enamorada de vos.

-¿Quién? 


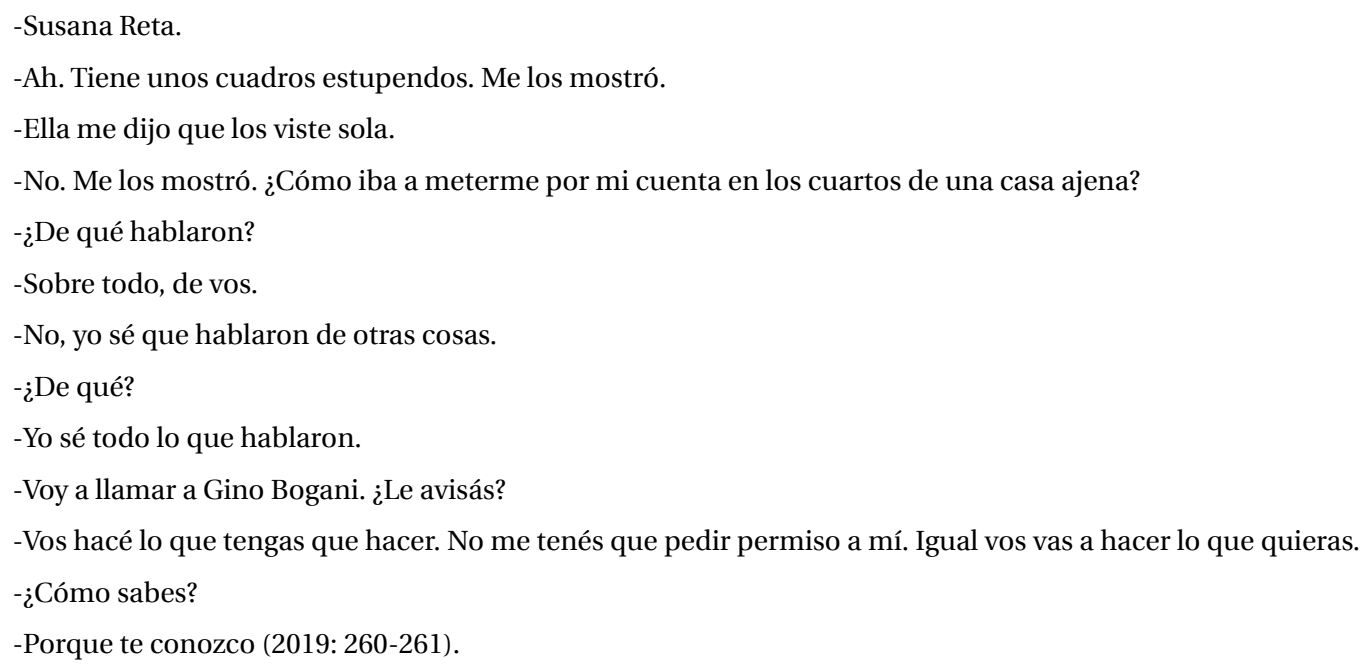

El ritmo de un relato puede descansar en la alternancia del sumario y de las escenas, como hemos dicho, pero también en la alternancia del iterativo y el singulativo (Genette, 1989: 199) como veremos a continuación. Leila Guerriero consigue ritmo alternando relato sumario -biografía del protagonista, por ejemplo- con escenas dialogadas. En el perfil de Guillermo Kuitca sus párrafos se estructuran de la siguiente forma: una descripción, que suele ser de alguna habitación de su casa -la cocina, el estudio, el salón, el recibidor, etc.- o una narración descriptiva sobre algún periodo de su vida, y a continuación un diálogo con Kuitca, en el que a menudo se ha suprimido la voz que pregunta (la voz del narrador) y solo se lee la respuesta a la pregunta, que suele ser contundente y dar información muy relevante sobre el personaje. Es decir, se alterna relato sumario con escenas (singulativas) dramáticas:

Empezó a tomar cocaína en 1983, un año después de haber iniciado la serie Nadie olvida nada, y siguió tomando, en forma sostenida y creciente, hasta 1987. [...]

- Estar en el taller, tomar, pintar, tenía algo que no pasaba de otro modo. La serie de Siete últimas canciones la hice completamente drogado. Había algo en la cocaína que no era lo que te dejaba hacer, sino lo que no te dejaba. [...]

Los cuadros de Tres días y Tres noches: parejas unidas en cópulas secas, una bruma lechosa sobre todo. El rastro violento de la felicidad cuando se acaba.

- Seguramente era lo que duraban esos días. Tres días y tres noches (Guerriero, 2013: 84-85).

Leila Guerriero también logra ritmo alternando las relaciones de frecuencia entre relato y diégesis. No solo el singulativo y el iterativo, es decir, contando una vez lo que ha ocurrido una vez y contando una vez o en una sola vez lo que ha ocurrido $\mathrm{n}$ veces; sino también contando $\mathrm{n}$ veces lo que ha ocurrido $\mathrm{n}$ veces y contando $\mathrm{n}$ veces lo que ha ocurrido una vez. En el extenso perfil sobre Bruno Gelber (2019) utiliza este recurso constantemente. Un ejemplo: cada vez que visita al protagonista en su casa narra su llegada, que transcurre de la misma forma con ligeras variaciones: una escena que sucede $n$ veces la narra n veces. Y cuando va por la enésima vez, Guerriero juega con ese recurso: la narra simplificándola, hace una 
pausa en la narración para introducir una prolepsis que nos anuncia que esas visitas a Bruno Gelber se repetirán durante un largo periodo de tiempo, "a lo largo de meses", y añade que el hecho de que él la llame "maravilla" significa un paso importante en la relación que se establece entre ambos.

Comparemos cómo está narrada la primera vez que llega a la casa y cómo se narra sucesivas veces. En la primera vez hay una minuciosa descripción del edificio y del portal de la casa antes de llegar a la escena que se repetirá durante todo el libro.

En el piso número doce espera Juana. Sostiene abierta una de las hojas de las puertas altísimas, dos metros de madera noble. Para abrirlas -desde adentro o desde fuera- hay que desconectar la alarma del departamento que permanece activada siempre. Juana es baja, menuda, de formas discretas pero contundentes: pechos definidos, caderas estrechas, muslos finos. Usa el cabello oscuro y lacio recogido [...].

- Hola, encantada, Leila.

- Encantada, cómo está. Juana.

Y por primera vez dice una frase que repetirá a lo largo de meses:

“- Pase, pase; el señor la está esperando”.

Siempre dirá "pase, pase" dos veces (Guerriero, 2019: 15-16).

En las sucesivas veces que narra la llegada ya no hace falta describir el edificio ni el portal: Guerriero va directa a la escena, una escena que se repetirá a lo largo del libro.

El viernes 5 de mayo a las seis de la tarde tengo que tocar el timbre varias veces en el piso doce. Hace frío, y la ciudad tiene un aspecto triste y congestionado. Juana atiende y avisa que ya baja, pero entonces un vecino abre la puerta y me deja pasar.

Mis pasos en el hall, el ascensor, la chicharra, Juana.

- Pase, pase: el señor la está esperando.

En la sala, frente a un té desmedido, él ejerce la misma maniobra de empuje para levantarse.

- Hola, Bruno.

- ¡Maravilla! ¿Cómo estás? (2019: 116).

En el tercer tercio del libro, la descripción de la llegada ya se ha convertido, gracias a las elipsis, en un texto con las resonancias rítmicas de un poema.

El 14 de septiembre.

Mis pasos en el hall.

El ascensor.

La chicharra.

Juana.

- Pase, pase: el señor la está esperando.

El recodo del recibidor, la sala. 
- ¡Tessssoro! -dice, exagerando la ese, mientras tracciona con las manos sobre los apoyabrazos de la silla y luego con los puños sobre la mesa para levantarse (2019: 262-263).

Esa introducción a las largas escenas que transcurren en la casa de Bruno Gelber es como el arranque de un cuento infantil, el "érase una vez". Sitúa al lector en un punto de tensión, hace que se pregunte qué va a suceder esta vez en la casa, qué nuevos descubrimientos haremos de Bruno Gelber. Le da tensión y además le da ritmo. Podemos observarlo en este ejemplo de iteración:

Pulsa el teléfono. Juana atiende.

-Sí, ¿̇me traes unas pastillas?

Pulsa el teléfono. Juana atiende.

-¿Qué pasó con la luz, que está baja?

Pulsa el teléfono. Juana atiende.

-No se olvide que tiene que ir a comprara, para la cena, crema.

Pulsa el teléfono, Juana atiende.

-Prenda la luz del balcón, como le dije.

Hay días así (2019: 265-266).

\subsubsection{Modo y $\mathrm{voz}$}

Es importante distinguir quién narra (voz) y quién ve (modo o punto de vista desde el que se narra). Sobre la perspectiva se ha dado históricamente una gran confusión entre modo y voz; entre quién ve y quién habla. Cleanth Brooks y Robert Penn Warren proponían en 1943 (Genette, 1989: 241-242) el término "foco narrativo" como equivalente de "punto de vista" y definían cuatro tipologías: narrador omnisciente, que Todorov simboliza mediante la fórmula Narrador $>$ Personaje (narrador sabe más que el personaje) o dice más de lo que sabe personaje alguno; Narrador = Personaje, el narrador dice lo que sabe tal personaje, es el relato con punto de vista; Narrador < Personaje, el narrador dice menos de lo que sabe el personaje, es el relato objetivo.

Genette, por su parte, utiliza el término de focalización. Y habla de:

- relato no focalizado o de focalización cero, que sería el relato clásico en el que narrador sabe más que el personaje

- focalización interna ya sea fija, variable o múltiple, en el que el narrador dice lo que sabe tal personaje

- focalización externa, en la que el narrador sabe solo lo que observa desde fuera.

En cuanto a la voz, Genette distingue dos tipos de relatos: heterodiégetico, de narrador ausente de la historia que cuenta; homodiegético, de narrador presente como personaje de la historia, que puede ser a su vez que el narrador sea el protagonista de su relato o que el narrador desempeñe un papel secundario de observador o de testigo. Leila Guerriero se manifiesta en la mayoría de sus textos como un narrador homodiegético débil: desempeña un papel secundario como observador. En ocasiones tan secundario que desaparece de la historia y podría hablarse de un narrador heterodiegético, pero con una pregunta o con una mínima reflexión hace al lector consciente de que sigue allí. En su caso sería intere- 
sante aplicar la tipología de Aare (2016), que distingue entre: narrador en tercera persona reconstruida, que no ha estado presente en la realidad, el relato se reconstruye con testimonios y documentos; narrador en tercera persona retocada: ha estado presente en la realidad, pero desaparece del texto, el relato se construye a partir de la observación directa; narrador en tercera persona atenuada: ha estado presente en la realidad, pero aparece solo ocasionalmente en el texto, el relato se construye a partir de la observación directa; narrador en primera persona consonante: está enfocado en la experiencia del narrador, las escenas se construyen a partir de la observación directa; narrador en primera persona disonante: está enfocado en el relato de las experiencias del autor del texto, las escenas se construyen a partir de la observación y la vivencia directa.

Esta tipología nos ayuda a hacer una primera clasificación dentro de sus perfiles: en sus piezas sobre personajes fallecidos como la poeta uruguaya Idea Vilariño (Idea Vilariño. Esa mujer, 2013), por ejemplo, se manifiesta como una tercera persona reconstruida: no ha estado presente en la realidad, el relato se reconstruye con testimonios y documentos. Guerriero habla con todo un elenco de personajes que conocieron a la poeta-hermanos, amigos, críticos-, busca testimonios escritos, voces grabadas, fotos, visita los lugares que habitó y bucea en sus poemas. Por ejemplo, para escribir sobre su funeral rescata noticias en la hemeroteca:

"No fue un acto de multitudes", decía el artículo del diario El País, de Uruguay, que anunciaba que el 28 de abril de 2009 había muerto Idea Vilariño. Tres meses más tarde, el 24 de julio, el suplemento Cultural del mismo diario le dedicaba una edición completa, y la nota de portada firmada por Rosario Peyrou comenzaba citando una frase del crítico Emir Rodríguez Monegal:

"Algún día seremos recordados como los contemporáneos de Idea Vilariño" (Guerriero, 2013: 49).

En este tipo de perfiles habría que referirse, en cuanto al modo, a un relato no focalizado o de focalización cero, que sería el relato clásico en el que narrador sabe más que el personaje, desgrana su vida vista en la distancia, sabiendo qué le sucederá y cómo terminará: retomando el caso de Idea Vilariño, el perfil comienza con su funeral, por lo tanto, el narrador sabe mucho más que su personaje. Y también hay una focalización interna en la que el narrador dice lo que sabe tal personaje, es decir, volviendo a Idea Vilariño, el narrador desgrana lo que cuentan los personajes que entrevista para el perfil. En una segunda distinción, que correspondería a los perfiles sobre personajes vivos, hablaríamos, en cuanto a la voz, de una tercera persona atenuada: ha estado presente en la realidad, pero aparece solo ocasionalmente en el texto y el relato se construye a partir de la observación directa. En cuanto al modo, se trataría de focalización interna -narrador dice lo que sabe tal personaje- con largos pasajes de focalización externa -narrador sabe solo lo que observa- y en raras ocasiones no focalización -el narrador sabe más que el personaje-.

En el perfil de Facundo Cabral (2013) Guerriero utiliza los tres tipos de focalización. Está escrito en una tercera persona atenuada -el narrador aparece ocasionalmente en el texto-: podemos leer las respuestas de Cabral, pero no las preguntas que el narrador le hace; o las preguntas de Cabral, pero no las respuestas del narrador.

- Decirme si hay algún pozo. Yo sólo puedo mirar hacia adelante. No puedo ver hacia abajo o hacia arriba.

El bastón de madera palpa las baldosas de la Plaza San Martín, una de las zonas más elegantes de la ciudad.

- ¿Me acompañas a pagar el teléfono? (2013: 199) 
El texto tiene focalización interna -el narrador dice lo que sabe Cabral-; intercalado con breves pasajes de focalización externa-el narrador sabe solo lo que observa-, como es el caso de los diálogos de Cabral con la gente que se encuentra por la calle, en los que el narrador es un mero observador, actúa como una cámara que recoge lo que tiene delante:

En la oficina de pagos de la empresa de celulares, Facundo Cabral espera en la fila frente a una de las ventanillas.

- Adelante -dice una mujer, y Cabral avanza.

- Hola. ¿Cómo es tu nombre, mi amor?

- Ivana.

- Ivana, eres la luz de mi ventana, para mí la vida sin Ivana no es nada. ¿Cuánto

es, Ivana? [...]

Ivana sonríe, chequea algo en su computadora y pregunta:

- ¿Usted es Cabral, Rodolfo Enrique? (Guerriero, 2019: 201-202).

En el perfil-libro Opus Gelber (2019) se da una curiosa gradación en la aparición del narrador. El relato está narrado en primera persona, pero es una primera persona que a veces parece tercera persona atenuada. Al principio del libro, la primera persona aparece poco, pero va incrementándose su presencia a medida que transcurre el relato, y a medida que el narrador-periodista se va implicando más en la relación con su personaje-entrevistado. La relación de ambos es una especie de relación amorosa y en ella el narrador se convierte también en protagonista: aparece el personaje de Leila Guerriero. Y el personaje se deja seducir por Bruno Gelber. Ese proceso de seducción necesita ser narrado en primera persona. El personaje que es Leila Guerriero observa primero todo desde fuera-focalización externa-, el hogar de Bruno Gelber, al propio Bruno Gelber, a sus amigos. Y después de meses de encuentros y entrevistas, el personaje Leila Guerriero se convierte en parte de la vida de Bruno Gelber, en parte de la historia que está narrando.

Según lo estudiado, se podría decir que los perfiles de Leila están escritos en su mayoría en una tercera persona atenuada (ha estado presente en la realidad, pero aparece solo ocasionalmente en el texto, el relato se construye a partir de la observación directa) que, en ocasiones, cuando se trata de personajes fallecidos, se convierte en una tercera persona reconstruida, y en otras, como en el perfil de Bruno Gelber, pasa a una primera persona consonante e incluso disonante, es decir que narra sus propias experiencias y vivencias, aunque siempre de una forma sutil. Aplicando la terminología de Genette, pasa de un narrador heterodiégetico, ausente de la historia que cuenta; a homodiegético, presente como personaje de la historia, pero siempre desempeñando un papel secundario de observador o de testigo.

En cuanto a la perspectiva o modo, como ya hemos señalado, se puede hablar de focalización interna -narrador dice lo que sabe tal personaje- con largos pasajes de focalización externa -narrador sabe solo lo que observa- y en raras ocasiones no focalización -el narrador sabe más que el personaje- o incluso, retorciendo este último concepto, de falsa no focalización: Guerriero simula que sabe más que el personaje, pero no es cierto.

Esa complejidad en el modo y en la voz y la subversión de los cánones tradicionales del periodismo es lo que convierte la obra de Guerriero en una obra de calidad literaria. Pero sigamos analizándola y adentrémonos ahora en sus recursos literarios. 


\subsubsection{Recursos literarios}

¿Qué es el lenguaje literario? ¿Están escritos los perfiles de Leila Guerriero en lenguaje literario? José Domínguez Caparrós en su Introducción al comentario de textos (1985) afirma sobre el lenguaje literario:

(...) no han sido pocos los intentos de encontrar lo específico del lenguaje literario. El problema, que ya se había planteado de otra forma en la vieja Retórica, es saber si el lenguaje literario es diferente y, en caso de responder afirmativamente, respecto a qué difiere: ¿cuál es la norma de la que se aparta el lenguaje literario?, ¿cuál es la gramática de la lengua literaria? (1985:14).

Domínguez Caparrós propone un modelo de análisis de texto en el que distingue entre sistema y referencia. Dentro del sistema estaría la palabra (morfología), la frase (sintaxis) y la significación (semántica). A su vez, dentro de la palabra se estudian fenómenos que tenga que ver con esa unidad lingüística (rima, aliteración, paranomasia, juegos de palabras, entre otros) (1985: 35). En la frase se pueden producir cambios dentro de su estructura, lo que da lugar a procedimientos elípticos (asíndeton, parataxis...); ampliación de la estructura (paréntesis, concatenación de elementos, enumeración y paralelismo, polisíndeton); y variación en la ordenación de los elementos de la frase y en las concordancias (anacoluto, estilo indirecto, hipérbaton...) (1985: 53-54). Y en la significación puede haber cambios de sentido, lo que da lugar a los tropos.

En cuanto a la referencia, Domínguez Caparrós habla de designación: "Por designación entendíamos la referencia del lenguaje a una realidad extralingüística” (1985: 95). El profesor afirma que las figuras retóricas encuadradas en ese segmento del análisis de texto, "hacen alusión al contexto y/o al referente, se dan en una o varias palabras, sometidas a la prueba de la verdad, dan el resultado de «falso», y su entidad es circunstancial" (1985: 97).

El presente estudio utilizará el modelo de Domínguez Caparrós y destacará los recursos más eficaces para lograr una expresión literaria intensa y propia. Los que tienen mayor aplicación en el caso de Guerriero son: aliteración, juegos de palabras, paralelismo, elipsis, variaciones en la ordenación de los elementos de la frase y en las concordancias como el anacoluto; tropos como la metáfora, el oxímoron, la antítesis, la comparación, la metonimia- sinécdoque; y las figuras retóricas de la designación como la hipérbole, el pleonasmo o la ironía.

$\mathrm{Al}$ aplicar este análisis al estudio de la palabra en los perfiles de Guerriero, se encuentran con frecuencia recursos como la aliteración (predominio de un mismo sonido en las sílabas acentuadas de un mismo grupo de palabras), la paranomasia (agrupación de palabras con parentesco etimológico o semejanza fónica casual), la derivación (empleo de palabras derivadas de una misma raíz), los juegos de palabras y todos los fenómenos que tengan que ver con la fonética. Ese es uno de los rasgos en el que se percibe claramente la influencia de sus lecturas poéticas. Veamos un ejemplo del perfil Guillermo Kuitca. Un artista del mundo inmóvil:

Hay una habitación de hotel, hay una ventana, hay un edredón tiñéndose de rojo con la luz del atardecer. Hay una ciudad llamada Columbus, en el estado americano de Ohio y hay, en la habitación, un hombre que escribe (...) (2013: 77).

En este fragmento del perfil de Guillermo Kuitca se producen varias aliteraciones: "hay -habitación - hombre - Ohio"; "habitación - ventana"; "edredón - rojo - atardecer". Además de paralelismo: en tres líneas se repite cinco veces la palabra "hay" y con idéntica estructura gramatical. 
Es habitual que en la frase no aparezcan explícitos todos los elementos de que, según un análisis lógico, constaría. Este procedimiento se puede calificar de elíptico (Domínguez Caparrós, 1985: 57). Guerriero utiliza un gran abanico de figuras elípticas, como el asíndeton o carencia de cópula entre dos o más miembros y la parataxis, preferencia por la coordinación sobre la subordinación; y a su vez, figuras que hacen la que frase se vea aumentada como el polisíndeton, que consiste en la coordinación de varios elementos lingüísticos con abundantes conjunciones (1985: 60).

Las figuras elípticas en los textos de Guerriero provocan un efecto semejante a la precipitación: aumentan la velocidad y hacen que el texto adquiera un ritmo trepidante. Ejemplo de asíndeton en Guillermo Kuitca. Un artista del mundo inmóvil:

En todas hay camas vacías, cochecitos de bebés rodando por escaleras tremebundas en claras citas al Acorazado Potemkin, camas en las que duermen niños a punto de ser aplastados por un garrotazo de madre, sillas tumbadas, figuras humanas diminutas rodeadas por paredes del tamaño de olas de tsunami, parejas enredadas en cópulas estériles (2013: 81-82).

Otras figuras que utiliza la periodista son las relacionadas con la ordenación de los elementos de la frase o con la concordancia. Entre ellas el anacoluto, ruptura de concordancia en un período; el estilo indirecto libre es una especie de anacoluto, pues, mientras la construcción conserva las formas verbales y las personas del estilo indirecto, el orden de las palabras y el tono son los del estilo directo (Domínguez Caparrós, 1985: 63). O la mezcla de estilo directo e indirecto en este ejemplo de Guillermo Kuitca. Un artista del mundo inmóvil:

Usa un suéter claro, pantalón amplio, el pelo corto, la voz suavísima y lejana cuando dice miren quién llegó.

- Miren quién llegó (2013: 78).

También son habituales las figuras que tengan que ver con la significación, es decir, los tropos, como metáfora, oxímoron, antítesis, comparación, metonimia- sinécdoque. La metáfora es uno de los recursos literarios más utilizados por Guerriero. Por ejemplo, en el perfil de Guillermo Kuitca. Un artista del mundo inmóvil cuando describe lo que se encuentra en sus estanterías: "objetos abandonados por una marea distraída" (2013: 80). Tomemos el perfil Hebe Uhart. La escritora oculta (2013: 286-298), donde encontraremos metáforas y comparaciones muy creativas. Por ejemplo, en la frase: "declaración de principios de ese estado de discreción benévola en el que vive y bajo el que crujen las capas tectónicas de la tragedia humana", tenemos metáforas y sinestesia: crujen las capas tectónicas de la tragedia humana. Guerriero escribe sobre palabras que están "deliberadamente desamparadas bajo la lluvia ácida de 'como se llame”. Cuando habla, Hebe Uhart coloca las palabras "como si fueran piezas de un puzle". De su forma de escribir dice: "Sobre el telón de fondo de su mutismo tierno, de su tragedia enfurruñada, ella despliega la crueldad de la jauría”, donde encontramos también personificación del mutismo, de la tragedia. Las metonimias son muy frecuentes, así como el oxímoron: "era el secreto a voces de la literatura nacional".

En casi toda su obra abundan las metonimias, por ejemplo, en su perfil Nicanor Parra. Buscando a Nicanor (2013: 18-34): "su natural competitivo", "pintado por los punkies de las Cruces"; y las sinestesias, "en sus años altos"; "cíclopeo recelo", "huella feroz". En el perfil Máquina Fogwill (2013: 35-48), encontramos sinestesias, "tararea en tono quirúrgico, azul, indiferente". 
Domínguez Caparrós entiende por designación, “la referencia del lenguaje a una realidad extralingüística” (1985: 95). Entre sus figuras retóricas, destacan por su uso en Guerriero: la hipérbole (exageración más allá de lo verosímil), el pleonasmo (uso de palabras superfluas, redundantes), la antítesis (contraposición de dos pensamientos de amplitud sintáctica arbitraria -palabras, frases, períodos-), que a su vez está emparentada con el oxímoron; y por último, la ironía (expresar un pensamiento con un vocabulario que denota precisamente lo contrario).

En el perfil Nicanor Parra. Buscando a Nicanor (2013: 18-34) encontramos hipérbole: "Es un hombre, pero podría ser otra cosa: una catástrofe, un rugido, el viento". Que en el siguiente párrafo va aumentando: "Es un hombre, pero podría ser un dragón, el estertor de un volcán, la rigidez que antecede a un terremoto". Abundan también las antítesis: "Una fuerza inhumana en un mundo hecho por hombres".

La ironía es un recurso que utiliza muy a menudo. Mostremos un ejemplo en el perfil de Hebe Uhart. La escritora oculta (2012: 288): "No fue una lectora precoz ni tuvo tíos artistas o vocación de escritora", que son tres lugares comunes que se emplean a menudo en el periodismo para hablar de los orígenes de un escritor.

En El hombre del telón (2012), el perfil sobre el restaurador del telón del teatro Colón de Buenos Aires, el protagonista constantemente se refiere a sí mismo y cada frase empieza con el pronombre personal de primera persona "yo". En todo al perfil hay claros ejemplos de pleonasmo, y actúan precisamente como un recordatorio de lo solo que se encuentra ese hombre: es él mismo con su idea de cómo enmendar ese telón magnífico, una gran responsabilidad en la que nadie lo apoya. Y el final es una mezcla genial de pleonasmo en tono trágico con un punto irónico: “-Ahora yo ya no sé qué será de mí, pero no me importa" (2012: 289).

\subsection{Recursos del New Journalism}

Tom Wolfe describe el New Journalism como el periodismo que aplica las técnicas de la ficción realista. El periodista Robert S. Boynton, lo explica en el prólogo de The New New Journalism:

reproducción de diálogos enteros, más que los fragmentos que utiliza el periodismo de diario; construcción escena por escena, como en una película; incorporar varios puntos de vista, en vez de contar una historia solo desde la perspectiva del narrador; y prestar atención a detalles que transmiten el estatus del entrevistado como su apariencia y su comportamiento. Dicho con rigor, el New Journalism se lee como un relato (Boynton, 2005: xvi).

Guerriero utiliza parte de esas técnicas, por ejemplo, la construcción de escenas y la reproducción de diálogos enteros. Esta última técnica la lleva a sus últimas consecuencias en sus perfiles-libro. En Opus Gelber (2019) los diálogos ocupan varias páginas y ayudan a comprender la psicología del personaje y, también, el carácter de la relación que poco a poco se va creando entre la periodista -convertida ya en personaje de la historia- y el perfilado. Esta recreación de diálogos, en ocasiones aparentemente banales, es un recurso hallado en todos sus perfiles. A veces son diálogos que suceden en persona, otras veces son conversaciones telefónicas. Incluso en los casos en que el personaje a quien Guerriero llama no quiera hablar, no quiera concederle una entrevista, la periodista elige transcribir esa conversación en vez de contar que la persona se negó a darle una entrevista. 
La construcción de escenas es una de las constantes de Guerriero. En todos sus perfiles encontramos alguna escena en la que ella sitúa al personaje en su entorno con prolijas descripciones y lo hace actuar e incluso interactuar con otros personajes. El lector ve al entrevistado de una forma casi cinematográfica: cómo se mueve, cómo respira, cómo habla. Es lo que Tom Wolfe llama relatar la vida subjetiva o emocional de los personajes. Lo explica bien cuando describe cómo trabaja un periodista del New Journalism:

Parecía importante estar allí cuando se producían escenas dramáticas, para obtener el diálogo, los gestos, las expresiones faciales, los detalles del entorno. La idea era ofrecer una descripción objetiva completa, y algo más, algo para lo que los lectores siempre habían tenido que acudir a las novelas y relatos: la vida subjetiva o emocional de los personajes (Wolfe, 1972: 18).

Todo eso que explica Wolfe está en las escenas de Guerriero. Y tiene que ver también con su maestría en las descripciones y con otro rasgo del New Journalism: prestar atención a detalles que transmiten el estatus del entrevistado como su apariencia y su comportamiento. Guerriero describe la atmósfera: la luz, a la que concede gran importancia, el olor, las texturas... cada una de las sensaciones que pueden recoger nuestros sentidos. También, la forma de vestir del entrevistado y los detalles de su entorno.

A veces las escenas se fragmentan, empiezan en un párrafo, sigue un párrafo de información, y vuelve a la escena. En el perfil sobre la joven encarcelada por parricidio, Sueños de libertad (2012), Guerriero va a visitarla a la cárcel. Describe minuciosamente dónde está situada la prisión, cómo es su interior, lo que sucede cuando llaman a la presa y su primer encuentro con ella. En el siguiente párrafo continúa con otras informaciones, pero más tarde vuelve a esa primera conversación con la joven, y sigue esa misma técnica a lo largo de todo el perfil. Es como si la primera escena de la cárcel fuera una única escena con final pospuesto que se extendiera a lo largo de todo el perfil a modo de hilo conductor. Observemos el arranque de la escena en la página 37 :

Es 2008 y hace dos meses que llueve en la provincia de Jujuy. El camino que lleva hasta la Unidad Penal Número 3, una cárcel de mujeres que comparte predio con la Unidad Penal Número 2, de varones, es barro puro. A un lado y otro hay alambre, y un paisaje que insiste en la inocencia: eucaliptus, árboles frutales. La Unidad 3 es una cárcel chica: hay 21 mujeres, algunas con sus hijos. El edificio tiene forma de U [...].

- iiiTejerinaaaaaaaaaa!! -grita una celadora vestida de gris plomo.

- Hola.

Romina Tejerina tiene los modos de las misses: da un beso y se acomoda el pelo detrás de la oreja.

- Uy, mirá qué lindo pajarito (2012: 49).

\section{Conclusiones}

1. El perfil o profile es uno de los grandes géneros del New Journalism y del periodismo anglosajón en general. En las últimas tres décadas ha vivido un auge dentro del periodismo narrativo en español y entre las periodistas que han contribuido a ello se encuentra Leila Guerriero. Guerriero lleva ejerciendo el periodismo desde 1992, pero es a partir de 
2001 cuando empieza a especializarse en el género del perfil. En las dos grandes antologías dedicadas exclusivamente a su obra, Frutos Extraños (crónicas reunidas 2001-2008) (2012, Alfaguara) y Plano Americano (2013, Universidad Diego Portales), de la primera, de 16 textos periodísticos, 13 son perfiles y tres, crónicas; de la segunda los 21 textos son perfiles. Si a esto sumamos los dos libros-perfil publicados por Leila Guerriero, Una historia sencilla (2013, Anagrama) y Opus Gelber (2019, Anagrama), se comprueba que la mayor parte de la producción periodística de Guerriero está dedicada a los perfiles, en los que se ha convertido en una maestra.

2. A diferencia de una gran parte de los textos del Nuevo Periodismo Latinoamericano, en los perfiles de Leila Guerriero desaparece el yo-narrador. Están escritos en su mayoría en una tercera persona atenuada -ha estado presente en la realidad, pero aparece solo ocasionalmente en el texto, el relato se construye a partir de la observación directa- y en raras ocasiones es un narrador presente como personaje de la historia, pero siempre desempeñando un papel secundario de observador. En cuanto a la perspectiva o modo, se puede hablar de focalización interna -narrador dice lo que sabe tal personaje- con largos pasajes de focalización externa -narrador sabe solo lo que observa-y excepcionalmente de no focalización -el narrador sabe más que el personaje- o incluso, retorciendo este último concepto, de falsa no focalización: Guerriero simula que sabe más que el personaje, pero no es cierto. Esa complejidad en el modo y en la voz y la subversión de los cánones tradicionales del periodismo es uno de los rasgos que otorga originalidad a la obra de Guerriero.

3. El estilo de Leila Guerriero en sus perfiles está marcado por el ritmo y la musicalidad. Para obtener el ritmo utiliza las distorsiones temporales de orden -analepsis, prolepsis, acronías- y las de duración que tengan que ver con la frecuencia como la elipsis. Para obtener la musicalidad, emplea todos los recursos literarios a su alcance: aliteración, paranomasia, derivación, juegos de palabras y, en general, todos los relacionados con la fonética. También es muy habitual que utilice los relacionados con los elementos de la frase o con la concordancia -anacoluto, estilo indirecto libre- y con la significación -tropos como metáfora, oxímoron, antítesis, comparación, metonimia-sinécdoque-.

Así, el estilo de Guerriero adquiere una gran riqueza formal. Guerriero experimenta con los recursos literarios sin perder nunca de vista el contenido, es decir, forma y fondo van a la par. $\mathrm{Y}$ al mismo tiempo consigue que su escritura posea una musicalidad y un ritmo que la acercan en ocasiones a los de la poesía.

4. Guerriero toma del New Journalism ciertos recursos -recursos que a su vez están en la literatura de ficción- como son la construcción de escenas, la transcripción de diálogos enteros y la descripción de los detalles que indican el estatus del perfilado, desde su indumentaria y su apariencia física hasta su entorno; y deja fuera aquellos que no encajan con su estilo como es la variación en el punto de vista.

5. Como se ha comprobado, los perfiles de Leila Guerriero poseen unas particularidades que marcan un estilo propio y muy diferenciado. Su uso de recursos del New Journalism, la complejidad en el modo y la voz, unida a la variedad y riqueza de los recursos literarios empleados que, a su vez, logran que el ritmo y la musicalidad impregnen sus textos, nos llevan a afirmar que ha creado una forma muy personal de hacer periodismo, extremadamente rigurosa en las investigaciones, que pueden durar meses o años como en sus perfiles-libro; también muy rigurosa en la plasmación de la información que ha recopilado; pero a su vez muy creativa y original en la escritura. Por todo lo expuesto ante- 
riormente, producto de estudiar sus perfiles aplicando modelos de análisis utilizados para profundizar en las obras literarias, se puede concluir que Leila Guerriero ha creado una forma de escribir periodismo narrativo que acerca sus perfiles a la categoría de obra literaria.

\section{Referencias bibiliográficas}

Aare, C. (2016). A Narratological Approach to Literary Journalism: How an Interplay between Voice and Point of View May Create Empathy with the Other. Literary Journalism Studies, vol. 8, no. 1, 107-139.

Bardin, L. (1986). El análisis de contenido. Madrid: Akal.

Boynton, R. S. (2005). The New New Journalism: Conversations with America's Best Nonfiction Writers on Their Craft. New York: Vintage.

Chillón, A. (2014). La palabra facticia: literatura, periodismo y comunicación. Bellaterra : Universitat Autònoma de Barcelona, Servei de Publicacions.

De la Serna (1996). Libro de estilo: El Mundo. Temas de Hoy.

De Sousa, J.M. (2003). Libro de estilo Vocento. Ed. Trea

Domínguez Caparrós, J. D. (1985). Introducción al comentario de textos. Madrid: Ministerio de Educación.

El País Ediciones (2014). Libro de estilo. Aguilar.

Fundación Gabo (23/05/2017). Lecciones de Leila Guerriero sobre reporteo, mirada y estilo. Recuperado de: https://fundaciongabo.org/es/noticias/articulo/lecciones-de-leila-guerriero-sobre-reporteo-mirada-y-estilo

Genette, G. (1989). Figuras III (1972). Barcelona: Lumen.

Grijelmo, A. (2014). El estilo del periodista.

Guerriero, L. (2019). Taller de periodismo narrativo de Leila Guerriero en la Fundación Gabo. Recuperado de: https:// fundaciongabo.org/es/recursos/relatorias/taller-de-periodismo-narrativo-para-la-informacion-cultural-maestra-leila Guerriero, L. (2013). Una historia sencilla. Barcelona: Anagrama.

Guerriero, L. (2013). Plano americano. Santiago de Chile: Ediciones Universidad Diego Portales.

Guerriero, L. (2012). Frutos extraños (crónicas reunidas 2001-2008) / Leila Guerriero. Madrid: Alfaguara.

Jaramillo Agudelo, D. (2012). Antología de crónica latinoamericana actual / Darío Jaramillo Agudelo (ed.). Madrid: Alfaguara.

Kerlinger, F. \& Lee, H. (2002). Investigación del comportamiento: Métodos de investigación en ciencias sociales. México: McGraw Hill Interamericana.

La Vanguardia (2004). Libro de redacción de La Vanguardia, Ariel.

López Pan, F. y Sánchez J.F. (1998). Tipología de géneros periodísticos en España. Hacia un nuevo paradigma. 
Rosendo, B. (2010). El perfil como género periodístico. Editorial Tecnos.

Vigara Tauste, A.M. (2001). Libro de estilo de ABC, Madrid: Planeta.

Vilamor, J.R. (2000). Redacción periodística para la generación digital, Madrid: Editorial Universitas.

Wimmer, R. D. y Dominick, J. R. (1996). La investigación científica de los medios de comunicación: una introducción a sus métodos. Barcelona: Bosch.

Wolfe, T. (1972). The birth of the new journalism; eyewitness report by Tom Wolfe. New York Magazine, vol. 14, 30-45.

Wolfe, T. (2000). El nuevo periodismo. Barcelona: Anagrama. 
